\title{
A Possible Regulatory Gene for the Molybdenum-Containing Cofactor in Aspergillus nidulans
}

\author{
By HERBERT N. ARST, JR, ${ }^{1,2 *}$ DAVID W. TOLLERVEY ${ }^{2}$ AND \\ HEATHER M. SEALY-LEWIS 3 \\ ${ }^{1}$ Department of Genetics, Ridley Building, The University, Newcastle upon Tyne NE1 7RU, \\ U.K. \\ ${ }^{2}$ Department of Genetics, University of Cambridge, Downing Street, Cambridge, CB2 3EH, \\ U.K. \\ ${ }^{3}$ Department of Biology, University of Essex, Wivenhoe Park, Colchester CO4 3SQ, U.K.
}

(Received 26 June 1981; revised 21 September 1981)

\begin{abstract}
Aspergillus nidulans has three molybdoenzymes, nitrate reductase, purine hydroxylase I and purine hydroxylase II. These three enzymes share a molybdenum-containing cofactor whose synthesis requires the integrity of five loci, designated $c n x A B C, c n x E, c n x F, c n x G$ and $c n x H$. Here we report the existence of a sixth locus, designated $c n x J$, which might be involved in the regulation of cofactor levels. When grown in the presence, but not in the absence, of tungstate or methylammonium, strains carrying $c n x J 1$ or $c n x J 2$ have reduced molybdoenzyme levels as judged both from growth properties and enzyme determinations. A new cryosensitive cnx $\mathrm{C}^{-}$ allele is also reported. Its phenotype at $37^{\circ} \mathrm{C}$ (but not $25^{\circ} \mathrm{C}$ ) shows some similarities to that of the two $c n x J^{-}$alleles. A structural role for the $\operatorname{cnx} C$ (or $\operatorname{cn} x A B C$ ) product in the cofactor is tentatively suggested.
\end{abstract}

\section{INTRODUCTION}

The conversion of inorganic molybdate into molybdenum-containing moieties of many molybdoenzymes involves a number of common steps [see reviews by Hewitt \& Notton (1980), Johnson (1980), Scazzocchio (1980), and Brill (1980)]. In the ascomycete fungus Aspergillus nidulans, a molybdenum-containing cofactor, whose existence was first postulated by Pateman et al. (1964), is essential to nitrate reductase and two distinct purine hydroxylases (formerly designated xanthine dehydrogenases) [reviewed by Cove (1979) and Scazzocchio (1980)]. Mutations at any of five unlinked loci, designated cnxABC, cnxE, cnxF, $c n x G$ and $c n x H$, lead to loss of nitrate reductase, purine hydroxylase $I$ and purine hydroxylase II. It is at present uncertain whether the $\operatorname{cn} x A B C$ locus be a single gene where mutations fall into three intracistronic complementation groups or two contiguous genes, $\operatorname{cn} x A$ and $\operatorname{cn} x C$, with $c n x B^{-}$mutations being a double loss class [see discussion by Cove (1979) and Scazzocchio (1980)]. Arst et al. (1970) have presented evidence that the cnxE product is concerned with insertion of molybdenum into the cofactor. Using thermosensitive mutants, MacDonald \& Cove (1974) have shown that the $c n x H$ gene product is probably a structural component of the cofactor whereas the $c n x E$ and $c n x F$ products are not, indicating that they probably encode enzymes involved in cofactor biosynthesis.

Whilst studying nitrogen metabolite (i.e. ammonium) repression of the syntheses of enzymes and permeases involved in nitrogen source utilization in A. nidulans (Arst \& Cove, $1969,1973)$ we selected a number of mutants hypersensitive to the toxic ammonium analogue

* Requests for offprints should be sent to this author at the Newcastle address.

† Present address: Department of Biochemistry, University of California, San Francisco, Calif. 94143, U.S.A. 
methylammonium. Although these mutants were selected on medium containing nitrate as nitrogen source, all but one showed methylammonium hypersensitivity on a wide range of nitrogen sources. The remaining mutant showed interesting specificity in that it was hypersensitive only on nitrogen sources (such as nitrate) whose utilization requires catalysis by a molybdoenzyme. This mutation, plus an allelic one subsequently selected, defines an additional cofactor gene, designated cnxJ, which recombines freely with the previously identified cnx loci. There is no evidence that mutations in $c n x J$ can lead to loss of any or all of the three molybdoenzymes, but $c n x J^{-}$mutations effectively lower the cofactor concentration. Preliminary characterization of a cryosensitive $\operatorname{cnx} \mathrm{C}^{-}$allele is also reported. It is consistent with a structural role for the $c n x C$ product in the cofactor.

\section{METHODS}

Genetic techniques and strains. Genetic techniques were modified after Pontecorvo et al. (1953), McCully \& Forbes (1965) and Clutterbuck (1974). Markers carried by $A$. nidulans strains have been described previously (Clutterbuck, 1974; Cove, 1979; Scazzocchio, 1980, and references in these three articles) with the exception of $c n x J 1, c n x J 2$ and $c n x C 20$ described herein.

Growth testing. Growth testing of $A$. nidulans has been described previously (Arst \& Cove, 1969; Arst, 1981). Conidiospores of numerous independent strains were stab-inoculated on to solid media and growth was monitored after 2 to $4 \mathrm{~d}$. The minimal medium described by Cove (1966) was used throughout. It contains $1 \%(\mathrm{w} / \mathrm{v})$ D-glucose as carbon source. Nitrogen sources were present at final concentrations of $10 \mathrm{~mm}$ [nitrate, nitrite, nicotinate and 6-hydroxynicotinate as the sodium salts; ammonium as the (+)-tartrate], $5 \mathrm{mM}$ [L-proline, L-alanine, L-glutamate (monosodium salt), L-arginine (hydrochloride), glycine, $\gamma$-amino- $n$-butyrate, urea], $735 \mu \mathrm{m}$ (hypoxanthine) or $594 \mu \mathrm{M}$ (uric acid). For utilization of hypoxanthine as nitrogen source via purine hydroxylase II (following Scazzocchio et al., 1973), 5.5 $\mu \mathrm{M}$-allopurinol and $1 \mathrm{mM}$-sodium nicotinate were present. Methylammonium and caesium were added as the chlorides, tungstate and molybdate as the disodium salts and chlorate as the potassium salt. Unless otherwise stated, growth tests were done at $37^{\circ} \mathrm{C}$.

Selection and genetic characterization of cnxJ1, cnxJ2 and cnxC20. cnxJ1 was selected, using replica plating (Mackintosh \& Pritchard, 1963), after $N$-methyl- $N^{\prime}$-nitro- $N$-nitrosoguanidine mutagenesis (Alderson \& Hartley, 1969) of a strain of genotype pabaA1 mauA2 fwA1 (requiring $p$-aminobenzoate, lacking monoamine oxidase and therefore unable to catabolize methylammonium, having fawn conidial colour), because it results in inability to utilize nitrate as nitrogen source in the presence of $1 \mathrm{mM}$-methylammonium. $c n x J 2$ and $c n x C 20$ were selected, after ultraviolet mutagenesis of a strain of genotype yA2 pantoB 100 (having yellow conidial colour, requiring D-pantothenate) as conferring resistance to $5 \mathrm{mM}$-chlorate on appropriately supplemented glucose-minimal medium containing $5 \mathrm{mM}$-L-proline as nitrogen source in the presence, but not in the absence, of $20 \mathrm{mM}$-tungstate. All three mutations are recessive in diploids. $c n x J 1$ and $c n x J 2$ failed to complement in a diploid and to recombine to yield any $c n x J^{+}$progeny (able to utilize nitrate as nitrogen source in the presence of $10 \mathrm{mM}$-tungstate) out of about 2000 cross progeny tested. $c n x J 1$ and $c n x J 2$ are therefore allelic. They are also phenotypically indistinguishable. The map position of $c n x J$ is noted in Results. $c n x C 20$ was located by haploidization (McCully \& Forbes, 1965) to linkage group VIII. Eight $c n x^{+}$recombinants were recovered amongst about 70000 progeny from a cross of relevant partial genotype $c n x C 20 \times c n x B 11$. In diploids $c n x C 20$ complements $c n x A 5$ but fails to complement $\operatorname{cn} x B 11$ or $c n x C 3$.

Enzyme assays. Strains used for biochemical analysis carry pabaAl with the exception of the wild-type strain used in some of the experiments on nitrate and nitrite reductase levels, which carries the biotin auxotrophy biA1. (In the presence of appropriate supplementation, no effect of either biAl or pabaAl on any enzyme involved in nitrogen metabolism has ever been detected.) For all experiments involving methylammonium, strains carrying, in addition, mauA 2 were used. (No effect of mauA2 on enzymes other than monoamine oxidase has ever been detected.) Results are the average of at least two and usually three independent determinations. In some cases, results have been further confirmed by experiments done under slightly altered conditions for which data are not shown. Relative activities are reproducible to within $10-15 \%$ of the values shown.

For nitrate and nitrite reductase assays, mycelia were grown for $9 \mathrm{~h}$ at $37^{\circ} \mathrm{C}$ in appropriately supplemented shaken minimal medium (Cove, 1966) containing $1 \%(\mathrm{w} / \mathrm{v}) \mathrm{D}$-glucose as carbon source and $10 \mathrm{mM}$-L-proline plus either $10 \mathrm{~mm}$-nitrate or $10 \mathrm{~mm}$-nitrite (as indicated) as nitrogen sources. These growth conditions are strongly inducing for both enzymes. Tungstate (disodium salt) or methylammonium (chloride) at the final concentrations shown was present from the time of inoculation. Extraction procedures, determination of soluble protein in extracts and assay methods for nitrate reductase (EC 1.6.6.3) and nitrite reductase (EC 1.6.6.4) have been described previously (Rand \& Arst, 1977) except that nitrate reductase assays contained $10 \mathrm{~mm}$ (final concentration) sulphite (disodium salt) to inhibit nitrite reductase activity. 
For purine hydroxylase I and urate oxidase assays, mycelia were grown for $20 \mathrm{~h}$ at $25^{\circ} \mathrm{C}$ in appropriately supplemented shaken minimal medium (Cove, 1966) containing $1 \%(\mathrm{w} / \mathrm{v}) \mathrm{D}$-glucose as carbon source, $5 \mathrm{mM}$-urea as nitrogen source and $2.72 \mu \mathrm{M}$-2-thiouric acid as co-inducer. Tungstate (disodium salt) or methylammonium (chloride) at the final concentrations shown was present from the time of inoculation. Extraction procedures, determination of soluble protein in extracts and assay methods for purine hydroxylase I (EC 1.2.1.37) and urate oxidase (EC 1.7.3.3) have been described previously (Scazzocchio et al., 1973). Inhibition of purine hydroxylase I activity in vitro by tungstate cannot be followed using the standard assay because addition of tungstate to the assay mixture results in formation of a precipitate. Therefore tungstate inhibition of purine hydroxylase I in vitro was followed using $\mathrm{NAD}^{+}$as the final electron acceptor. In a reaction volume of $1 \mathrm{ml}$, the assay cell contained 100 mM-orthophosphate buffer pH 7.8, $2 \mathrm{mM} \mathrm{NAD}^{+}, 100 \mu \mathrm{M}$-hypoxanthine and $100 \mu$ cell-free extract. The reaction was followed at $340 \mathrm{~nm}$ with a reference cell, omitting the hypoxanthine (Lewis et al., 1978).

\section{RES ULTS}

\section{Growth properties of cnxJ- strains}

Mutations at the $c n x A B C, c n x E, c n x F, c n x G$ and $c n x H$ loci of $A$. nidulans have been recognized as resulting in inability to utilize the substrates of the three molybdoenzymes as nitrogen sources whilst not affecting ability to utilize the products of their reactions [reviewed by Cove (1979) and Scazzocchio (1980)]. Loss of nitrate reductase results in inability to utilize nitrate but not nitrite. Loss of purine hydroxylase I results in inability to utilize hypoxanthine but not uric acid. Loss of purine hydroxylase II results in inability to utilize nicotinate but not 6-hydroxynicotinate. If allopurinol is present to inhibit purine hydroxylase I and a low concentration of nicotinate is present to induce purine hydroxylase II, the oxidation of hypoxanthine is catalysed by purine hydroxylase II and loss of purine hydroxylase II results in inability to utilize hypoxanthine but not uric acid. cnxJ1 and cnxJ2 differ in phenotype from mutations at the five previously identified $c n x$ loci in that they do not affect, at either $25^{\circ} \mathrm{C}$ or $37^{\circ} \mathrm{C}$, utilization of nitrate, hypoxanthine, nicotinate or hypoxanthine in the presence of allopurinol and nicotinate (Table 1) unless tungstate or methylammonium is present (Table 2). Nicotinate is too poor a nitrogen source for convincing differences in inhibitor tolerance to be observed but $c n x J^{-}$strains are clearly hypersensitive when nitrate, hypoxanthine or hypoxanthine in the presence of nicotinate and allopurinol serves as nitrogen source. On a large number of other nitrogen sources tested, including nitrite and uric acid, $c n x J^{-}$strains are indistinguishable from wild-type over a range of toxic and subtoxic concentrations of tungstate and methylammonium.

Differential sensitivity of nitrate reductase levels to tungstate in $c n x J^{-}$strains can also be observed on chlorate-containing media. The basis for chlorate toxicity to growth of $A$. nidulans is controversial, but it probably involves to some extent nitrate reductase-catalysed reduction to chlorite because many mutants lacking nitrate reductase are chlorate resistant [see Cove $(1976 a, 1979)]$. Moreover, at least some mutants which lack nitrate reductase but are nevertheless chlorate sensitive become chlorate resistant in the presence of subtoxic tungstate concentrations (Arst et al., 1979). In the presence, but not absence, of 10 to $20 \mathrm{~mm}$-tungstate, $c n x J^{-}$strains, but not wild-type strains, are partially resistant to 1 to $20 \mathrm{~mm}$ (according to nitrogen source) chlorate on a number of nitrogen sources including L-proline (shown in Table 2), L-alanine, L-glutamate, L-arginine, glycine, $\gamma$-amino- $n$-butyrate, uric acid and urea.

Differential sensitivity of purine hydroxylase I levels to tungstate in $c n x J^{-}$strains can also be observed on 2-thioxanthine media. 2-Thioxanthine, after oxidation to 2-thiouric acid, mainly catalysed by purine hydroxylase I, prevents the conversion of yellow to green conidial pigment (Darlington \& Scazzocchio, 1967; Alderson \& Scazzocchio, 1967). Mutants lacking purine hydroxylase I (e.g. $c n x C 3$ in Table 2) are resistant to 2-thioxanthine (but not to 2 -thiouric acid). Tungstate partially protects $c n x J^{-}$but not wild-type strains against the effect of 2-thioxanthine (Table 2). 
Table 1. Utilization of molybdoenzyme substrates as nitrogen sources by wild-type and various mutant cnx strains

Growth scores: - , residual, nitrogen-starved growth; \pm , weak growth; + to +++ , increasing levels of growth. Growth scores on different media are not necessarily equivalent. cnxC3 is a typical non-leaky $c n x^{-}$mutation.

\begin{tabular}{|c|c|c|c|c|c|c|c|c|c|}
\hline \multirow{3}{*}{$\begin{array}{l}\text { Relevant } \\
\text { genotype }\end{array}$} & \multicolumn{9}{|c|}{ Growth with nitrogen source and temperature shown } \\
\hline & \multicolumn{2}{|c|}{$\overbrace{}^{\mathrm{NO}_{3}{ }^{-}}$} & \multicolumn{2}{|c|}{ Hypoxanthine } & \multicolumn{2}{|c|}{ Nicotinate } & \multicolumn{2}{|c|}{$\begin{array}{l}\text { Hypoxanthine in } \\
\text { presence of nicotinate } \\
+ \text { allopurinol }\end{array}$} & \multirow{2}{*}{$\begin{array}{c}\mathrm{NO}_{3}{ }^{-} \text {in presence } \\
\text { of } 33 \mathrm{~mm}-\mathrm{MoO}_{4}{ }^{2-} \\
\text { in strain also } \\
\text { carrying cnxE14 } \\
37^{\circ} \mathrm{C}\end{array}$} \\
\hline & $25^{\circ} \mathrm{C}$ & $37^{\circ} \mathrm{C}$ & $25^{\circ} \mathrm{C}$ & $37^{\circ} \mathrm{C}$ & $25^{\circ} \mathrm{C}$ & $37^{\circ} \mathrm{C}$ & $25^{\circ} \mathrm{C}$ & $37^{\circ} \mathrm{C}$ & \\
\hline Wild-type $\left(c n x^{+}\right)$ & $++t$ & +++ & +++ & +++ & +++ & +++ & ++ & $++t$ & +++ \\
\hline$c n x J 1$ and $J 2$ & +++ & +++ & +++ & $+t+$ & $+t+$ & $+t+$ & +++ & +++ & - \\
\hline $\operatorname{cn} x \mathrm{C} 20$ & - & +++ & - & ++ & - & + & - & \pm & - \\
\hline $\operatorname{cnx} C 3$ & - & - & - & - & - & - & - & - & - \\
\hline
\end{tabular}

$c n x E^{-}$mutants can be supplemented by growth in the presence of high molybdate concentrations for restoration of molybdoenzymes as observed by growth tests, enzyme measurements, and cofactor assays (Arst et al., 1970; Ketchum \& Downey, 1975). Because of the pattern of molybdate toxicity, nitrate reductase is the molybdoenzyme most readily studied for supplementation (Arst et al., 1970). High molybdate concentrations restore the ability of $c n x E^{-}$strains to utilize nitrate as nitrogen source (Table 1). $c n x J^{-}$mutations abolish molybdate supplementation of $c n x E^{-}$lesions: unlike $c n x E 14$ single mutants, $c n x J 1$ or $c n x J 2$ cnxE14 double mutants are unable to utilize nitrate as nitrogen source in the presence of $33 \mathrm{~mm}$-molybdate (Table 1). Nevertheless, $c n x J^{-}$mutants do not affect molybdate toxicity (Table 2), indicating that they do not affect molybdate uptake [see Arst \& Cove (1970) and Arst et al. (1970)].

Can a mutation at another cnx locus have a phenotype similar to that of cnxJ- mutations?

At $37^{\circ} \mathrm{C}$ the growth properties of $c n x C 20$ strains are rather similar to those of $c n x J^{-}$ strains (Tables 1 and 2). A clear difference does, however, emerge on media containing substrates of purine hydroxylase II: $c n x C 20$ strains scarcely utilize nicotinate or hypoxanthine plus allopurinol and nicotinate. At $25^{\circ} \mathrm{C} c n x C 20$ has a phenotype very similar to fully mutant $c n x C^{-}$alleles such as $c n x C 3$ (Table 1), thus differing sharply from $c n x J 1$ and cnxJ2.

The basis for $\mathrm{Cs}^{+}$toxicity is unclear (Arst \& Page, 1973; Arst \& Cove, 1973; Hynes, 1974), but it can be utilized as an in vivo probe of levels of enzymes involved in nitrogen nutrition. Resistance to $\mathrm{Cs}^{+}$correlates with an increased rate of utilization of the nitrogen source, presumably leading to higher intracellular ammonium pools (as exogenous ammonium protects against $\mathrm{Cs}^{+}$toxicity) (Arst \& Cove, 1973; Bailey \& Arst, 1975; Bailey et al., 1979; Arst et al., 1980; Arst \& Bailey, 1980). Similarly, $\mathrm{Cs}^{+}$hypersensitivity is associated with reduced utilization of the nitrogen source (Rand \& Arst, 1977; Jones et al., 1981; Arst et al., 1981). At $37^{\circ} \mathrm{C}$, cnxC20 but not $c n x J 1$ or $c n x J 2$ leads to hypersensitivity to $\mathrm{Cs}^{+}$on nitrate and hypoxanthine as nitrogen sources (Table 2). This suggests that cnxC20 reduces nitrate reductase and purine hydroxylase I levels whereas $c n x J 1$ and $c n x J 2$ do not.

\section{Molybdoenzyme levels in cnxJ- strains}

The data in Table 3 show that, in agreement with its phenotype in growth tests, cnxJ1 leads to a two-fold reduction in nitrate reductase levels when growth takes place in the presence of tungstate or methylammonium but probably does not affect nitrate reductase levels in the absence of inhibitors. The specificity of the effect is confirmed by its absence when nitrite 


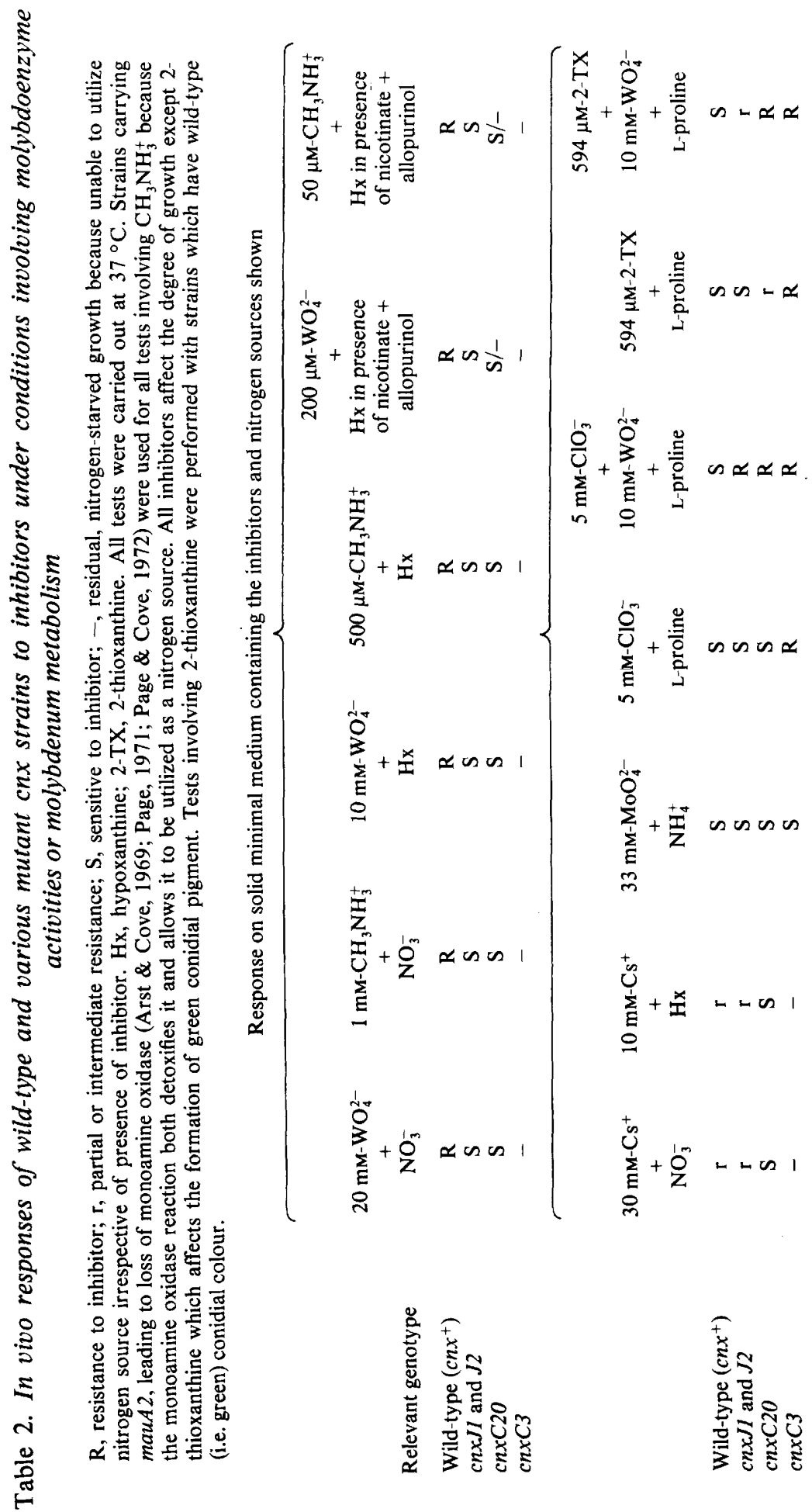




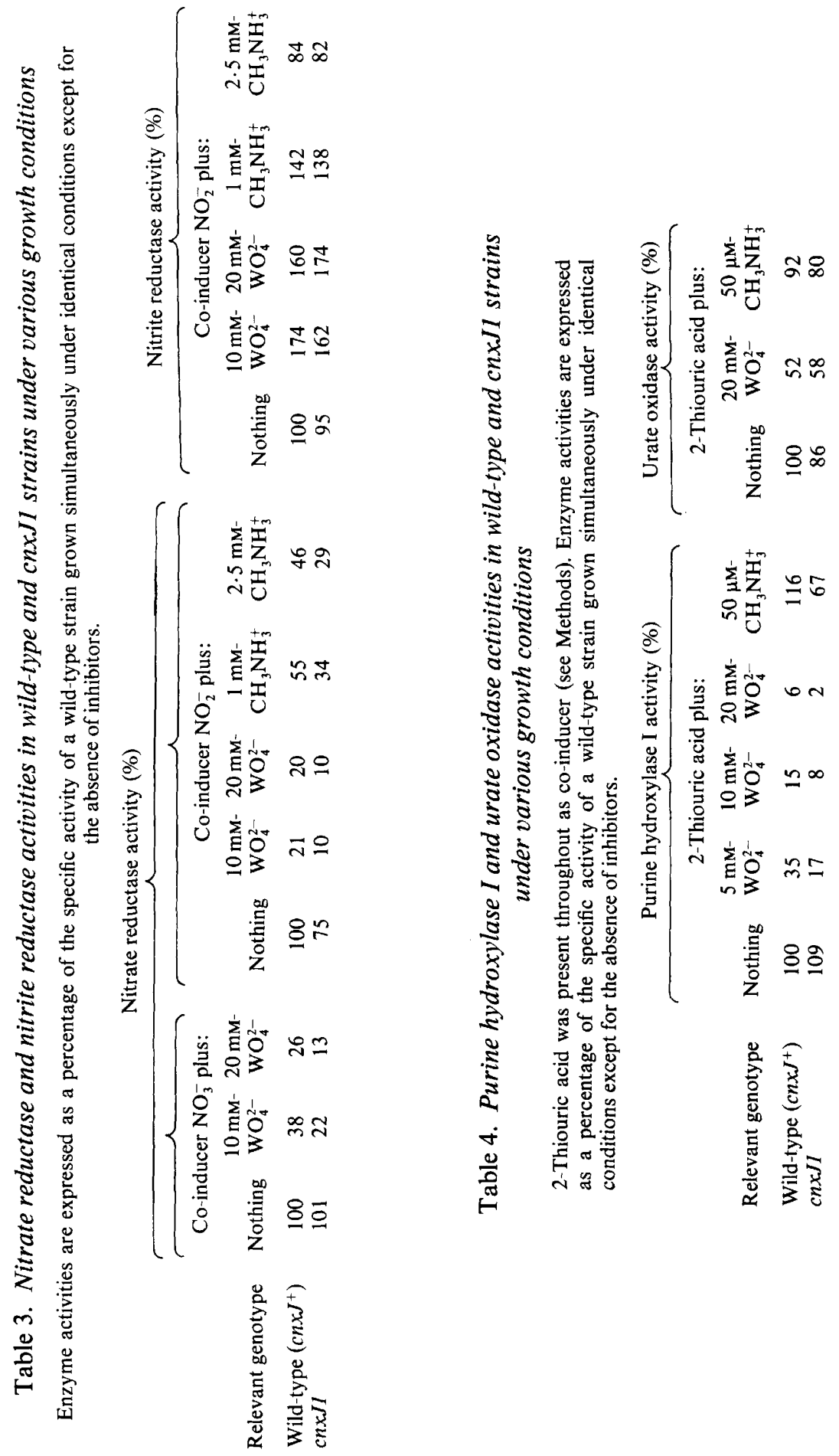


reductase is assayed. As both nitrate and nitrite can induce these enzymes (Pateman et al., 1967), nitrite induction was generally preferred for these experiments to avoid possible differences in the degree of induction arising from differences in the rate of nitrate reduction. Just as many mutants lacking nitrate reductase have elevated levels of nitrite reductase (Pateman et al., 1967; Cove, 1976a), the reduction of nitrate reductase levels by tungstate or methylammonium leads to elevated nitrite reductase levels except at the higher methylammonium concentration where inhibition of protein synthesis (Arst \& Page, 1973) might override it.

A similar two-fold effect of $c n x J 1$ on purine hydroxylase I levels in mycelia grown in the presence of tungstate or methylammonium is seen in Table 4 where urate oxidase serves as the specificity control. The gratuitous inducer 2-thiouric acid (Scazzocchio \& Darlington, 1968; Sealy-Lewis et al., 1978; Philippides \& Scazzocchio, 1981) was used to avoid differential degrees of induction. It is possible that reduced induction accentuates the cnxJphenotype when hypoxanthine serves as nitrogen source because uric acid, the product of the purine hydroxylase I reaction, is the physiological co-inducer (Scazzocchio, 1973; Philippides \& Scazzocchio, 1981). A similar accentuation of $c n x J^{-}$phenotype might apply in growth tests involving purine hydroxylase II where 6-hydroxynicotinate, the product of the reaction with nicotinate, is the physiological co-inducer (Sealy-Lewis et al., 1979).

To confirm that the cnxJ $J^{-}$phenotype is only revealed by growth in the presence of tungstate or methylammonium, the degrees of inhibition of nitrate reductase and purine hydroxylase I activities in cell-free extracts of a $c n x J 1$ and a wild-type strain were compared over a range of inhibitor concentrations. For both inhibitors much higher concentrations are necessary to achieve inhibition in vitro as compared to in vivo. In vitro no differences between the cnxJl and wild-type strains could be detected: $66 \mathrm{mM}$-tungstate and 100 mM-methylammonium inhibited nitrate reductase of both strains by about $50 \%$ as did $1.05 \mathrm{M}$-tungstate and $1 \mathrm{M}$-methylammonium in the case of purine hydroxylase $\mathrm{I}$.

Nitrate reductase activity could not be detected in extracts of two cnxC20 strains grown at $37^{\circ} \mathrm{C}$, although full induction was evident from nitrite reductase levels (data not shown).

\section{Map position of cnxJ}

Haploidization (McCully \& Forbes, 1965) located cnxJl to linkage group VII. This linkage group contains two other genes whose integrity is necessary to one or more molybdoenzymes, the cofactor gene $c n x F$ and $h x B$, a gene whose product is probably involved in a post-transcriptional modification essential to purine hydroxylases I and II (Scazzocchio, 1980). However, mapping crosses showed free recombination between cnxJ1 and both $c n x F 8$ and $h x B 13$. Further crosses located $c n x J 1$ (designated mahA1O in earlier publications) about 4 centimorgans from the prn gene cluster involved in L-proline catabolism but on the side opposite to that of the $s F$, panto $B$ and nim $O$ genes (Arst \& MacDonald, 1978). This position makes it useful as a flanking marker in fine-structure mapping of the prn cluster (Arst \& MacDonald, 1978; Arst et al., 1981).

\section{DIS CUS SION}

Designation of cnxJ as a gene affecting the molybdenum-containing cofactor. The fact that $c n \times J^{-}$mutations only affect levels of the three molybdoenzymes strongly suggests that they affect the molybdenum-containing cofactor and thus define a sixth cnx locus in $A$. nidulans. The nature of the two inhibitors which reveal the $c n x J^{-}$phenotype is entirely consistent with this proposal. Tungstate, a molybdate analogue, is probably able to lower the concentration of active molybdenum-containing cofactor by competition with molybdate for uptake into the cell and, once inside, for incorporation into the cofactor (Arst, 1968; Arst \& Cove, 1970; 
Arst et al., 1970; Sorger et al., 1974; Dantzig et al., 1978). Synthesis of the molybdenum-containing cofactor is apparently strongly reduced when wild-type $A$. nidulans is grown in the presence of ammonium (Garrett \& Cove, 1976) and it is quite possible that methylammonium can mimic this effect (Arst \& Cove, 1969, 1973; Arst \& Page, 1973; Bartnik et al., 1973; Hynes, 1974). Thus, although tungstate and methylammonium probably have almost nothing in common structurally or metabolically, they might share the ability, albeit through different means, to reduce molybdenum-containing cofactor concentrations.

This $c n x$ designation derives further support from the fact that a leaky mutation, $\operatorname{cn} x C 20$, in one of the five previously established $\operatorname{cn} x$ loci has a phenotype at $37^{\circ} \mathrm{C}$ which is somewhat similar to that of the two $c n x J^{-}$mutations. The fact that the $c n x C 20$ phenotype also differs strikingly in some respects from that of $c n x J 1$ and $c n x J 2$ is hardly surprising in view of the likelihood that the two gene products concerned play extremely different roles (vide infra).

Role of cnxJ. In assessing the role of the cnxJ gene, the key question is whether $c n x J 1$ and $c n x J 2$ result in complete loss of $c n x J$ function or whether a deletion of the $c n x J$ gene would have a more extreme phenotype, such as that of mutations at the other five cnx loci. At present the only evidence is negative: despite the characterization of very large numbers of mutations leading to loss of nitrate reductase, purine hydroxylase I and purine hydroxylase II, spontaneous or induced by a variety of mutagens and selected using a number of different techniques (Pateman et al., 1964; Alderson \& Scazzocchio, 1967; Alderson \& Hartley, 1969; Alderson \& Scott, 1971; Scott \& Alderson, 1971: Cove, 1976b, 1979; Scott et al., 1977; Scazzocchio, 1980), no $c n x J^{-}$mutation leading to lack of utilization of substrates of any or all of the three molybdoenzymes has even been obtained. Unless the cnxJ product has some additional and essential role(s), it therefore seems extremely unlikely that mutations in $c n x J$ can lead to loss of the molybdoenzymes. If the $c n x J$ product be dispensable for cofactor synthesis, it is almost certainly not a structural component of the cofactor. It could only be an enzyme involved in cofactor synthesis if it catalyses a reaction which proceeds spontaneously at an appreciable rate or which is catalysed by an alternative enzyme or which enhances the affinity of the cofactor for the three apoenzymes without significantly affecting holoenzyme efficiencies. A more attractive hypothesis, formally equivalent to the third of these possibilities on present evidence, is that $c n x J 1$ and $c n x J 2$ lead to a reduction in cofactor concentration. On this model $c n x J$ might be a positive-acting regulatory gene whose product is necessary for a high, but not a moderate, level of cofactor synthesis. [Under most growth conditions, the cofactor is probably present in excess (Johnson, 1980).] It would not, however, be easy to propose a physiological role for such a regulatory gene. Cofactor synthesis seems not to be regulated by the positive-acting regulatory genes controlling nitrate reductase or purine hydroxylase I synthesis (Scazzocchio \& Darlington, 1967; Garrett \& Cove, 1976). Garrett \& Cove (1976) found no evidence for induction of cofactor synthesis by co-inducers of the three molybdoenzymes. In their experiments the only addition to the growth medium which influenced cofactor levels was ammonium, which apparently represses synthesis of a gene product(s) necessary for cofactor synthesis and/or inhibits an enzyme(s) involved in cofactor synthesis. The ability of the ammonium analogue methylammonium to reveal the $c n x J^{-}$phenotype would seem to argue against mediation of the ammonium effect by the $c n x J$ product.

Role of cnxC. As cnxC20 strains utilize nitrate well at $37^{\circ} \mathrm{C}$, it is possible that nitrate reductase from $c n x C 20$ strains is too labile to withstand extraction. This might suggest that the gene product concerned be a structural component of the cofactor. Two other examples where it has not been possible to extract enzymes from cryosensitive mutants of $A$. nidulans grown at a permissive temperature are known. A cryosensitive mutation in the structural gene for proline oxidase prevents detection of that activity in vitro (Jones et al., 1981). And a cryosensitive mutation in $h x A$, the structural gene (Scazzocchio \& Sealy-Lewis, 1978; Scazzocchio, 1980) for the apoenzyme of purine hydroxylase I, has similarly thwarted all 
attempts at extraction of that enzyme [Lycan, Sealy-Lewis \& Scazzocchio as cited in Scazzocchio (1980)].

A structural involvement for the $\operatorname{cn} x C$ (or $\operatorname{cnx} A B C$ ) product would be easily reconciled with the fact that the phenotype of $c n x C 2 O$ is conditional (i.e. cryosensitive) with respect to nitrate reductase and purine hydroxylase I but virtually non-conditional with respect to purine hydroxylase II [although the requirement of purine hydroxylase II for the cofactor might simply be more stringent - see Scazzocchio (1980)]. On present evidence, however, this conclusion should be regarded as strictly tentative. The cofactor is likely to have a rather low molecular weight [see discussion by Johnson (1980) and Scazzocchio (1980)]. It is therefore difficult to see how it could include a polypeptide component in addition to that specified by $c n x H$.

H.N.A. thanks the Royal Society for the Smithson Research Fellowship and the Science Research Council for a research grant. D.W.T. thanks the Medical Research Council for a studentship and Darwin College, Cambridge for subsequent support. H.M.S.-L. thanks the Science Research Council for a research grant and Rachel P. Hodge for excellent technical assistance. Keith Rand was the first person to observe the tungstate hypersensitivity resulting from $c n x J 1$. We are very grateful to him and to Claudio Scazzocchio, Nigel Lewis and Don MacDonald for stimulating discussions.

\section{REFERENCES}

Alderson, T. \& Hartley, M. J. (1969). Specificity for spontaneous and induced forward mutation at several gene loci in Aspergillus nidulans. Mutation Research 8, 255-264.

Alderson, T. \& Scazzocchio, C. (1967). A system for the study of interlocus specificity for both forward and reverse mutation in at least eight gene loci in Aspergillus nidulans. Mutation Research 4, 567-577.

Alderson, T. \& ScoTT, B. R. (1971). Induction of mutation by $\gamma$-irradiation in the presence of oxygen or nitrogen. Nature New Biology 230, 45-48.

ARST, H. N., JR (1968). Genetic analysis of the first steps of sulphate metabolism in Aspergillus nidulans. Nature, London 219, 268-270.

ARST, H. N., JR (1981). Aspects of the control of gene expression in fungi. Symposia of the Society for General Microbiology 31, 131-160.

ARST, H. N., JR \& BaIley, C. R. (1980). Genetic evidence for a second asparaginase in Aspergillus nidulans. Journal of General Microbiology 121, 243-247.

Arst, H. N., JR \& Cove, D. J. (1969). Methylammonium resistance in Aspergillus nidulans. Journal of Bacteriology 98, 1284-1293.

ARST, H. N., JR \& Cove, D. J. (1970). Molybdate metabolism in Aspergillus nidulans II. Mutations affecting phosphatase activity or galactose utilization. Molecular and General Genetics 108, 146-153.

ARST, H. N., JR \& Cove, D. J. (1973). Nitrogen metabolite repression in Aspergillus nidulans. Molecular and General Genetics 126, 111-141.

Arst, H. N., JR \& MacDonald, D. W. (1978). Reduced expression of a distal gene of the prn gene cluster in deletion mutants of Aspergillus nidulans: genetic evidence for a dicistronic messenger in an eukaryote. Molecular and General Genetics 163, 17-22.

ARST, H. N., JR \& PAge, M. M. (1973). Mutants of Aspergillus nidulans altered in the transport of methylammonium and ammonium. Molecular and General Genetics 121, 239-245.

ARst, H. N., JR, MacDonald, D. W. \& Cove, D. J. (1970). Molybdate metabolism in Aspergillus nidulans I. Mutations affecting nitrate reductase and/or xanthine dehydrogenase. Molecular and General Genetics 108, 129-145.

Arst, H. N., JR, Rand, K. N. \& Bailey, C. R. (1979). Do the tightly linked structural genes for nitrate and nitrite reductase form an operon? Evidence from an insertional translocation which separates them. Molecular and General Genetics 174, 89-100.

Arst, H. N., JR, MacDonald, D. W. \& Jones, S. A. (1980). Regulation of proline transport in Aspergillus nidulans. Journal of General Microbiology 116, 285-294.

ARST, H. N., JR, Jones, S. A. \& Balley, C. R. (1981). A method for the selection of deletion mutations in the L-proline catabolism gene cluster of Aspergillus nidulans. Genetical Research 38, 171-195.

BAILEY, C. \& ARST, H. N., JR (1975). Carbon catabolite repression in Aspergillus nidulans. European Journal of Biochemistry 51, 573-577.

Bailey, C. R., Penfold, H. A. \& Arst, H. N., JR (1979). Cis-dominant regulatory mutations affecting the expression of GABA permease in Aspergillus nidulans. Molecular and General Genetics 169, 79-83.

Bartnik, E., Weglenski, P. \& Piotrowska, M. (1973). Ammonium and glucose repression of the arginine catabolic enzymes in Aspergillus nidulans. Molecular and General Genetics 126, 75-84.

BrILL, W. J. (1980). Biochemical genetics of nitrogen fixation. Microbiological Reviews 44, 449-467.

Clutterbuck, A. J. (1974). Aspergillus nidulans. In Handbook of Genetics, vol. I, pp. 447-510. Edited by R. C. King. New York: Plenum Press.

Cove, D. J. (1966). The induction and repression of nitrate reductase in the fungus $A$ spergillus nidulans. Biochimica et biophysica acta 113, 51-56. 
Cove, D. J. (1976a). Chlorate toxicity in Aspergillus nidulans. Studies of mutants altered in nitrate assimilation. Molecular and General Genetics 146, 147-159.

Cove, D. J. (1976b). Chlorate toxicity in Aspergillus nidulans: the selection and characterisation of chlorate resistant mutants. Heredity 36, 191-203.

Cove, D. J. (1979). Genetic studies of nitrate assimilation in Aspergillus nidulans. Biological Reviews 54, 291-327.

Dantzig, A. H., Zurowski, W. K., Ball, T. M. \& NASON, A. (1978). Induction and repression of nitrate reductase in Neurospora crassa. Journal of Bacteriology 133, 671-679.

Darlington, A. J. \& Scazzocchio, C. (1967). Use of analogues and the substrate-sensitivity of mutants in analysis of purine uptake and breakdown in Aspergillus nidulans. Journal of Bacteriology 93, 937-940.

Garrett, R. H. \& Cove, D. J. (1976). Formation of NADPH-nitrate reductase activity in vitro from Aspergillus nidulans niaD and cnx mutants. Molecular and General Genetics 149, 179-186.

HewitT, E. J. \& NotTon, B. A. (1980). Nitrate reductase systems in eukaryotic and prokaryotic organisms. In Molybdenum and MolybdenumContaining Enzymes, pp. 273-325. Edited by M. P. Coughlan. Oxford: Pergamon Press.

HyNES, M. J. (1974). Repression of enzymes of nitrogen catabolism by methylammonium and caesium chloride in strains of Aspergillus nidulans insensitive to ammonium repression. Molecular and General Genetics 132, 147-152.

Johnson, J. L. (1980). The molybdenum cofactor common to nitrate reductase, xanthine dehydrogenase and sulfite oxidase. In Molybdenum and Molybdenum-Containing Enzymes, pp. 345-383. Edited by M. P. Coughlan. Oxford: Pergamon Press.

Jones, S. A., ARst, H. N., JR \& MacDonald, D. W. (1981). Gene roles in the prn cluster of Aspergillus nidulans. Current Genetics 3, 49-56.

Ketchum, P. A. \& Downey, R. J. (1975). In vitro restoration of nitrate reductase: investigation of Aspergillus nidulans and Neurospora crassa nitrate reductase mutants. Biochimica et biophysica acta 385, 354-361.

Lewis, N. J., Hurt, P., Sealy-Lewis, H. M. \& Scazzocchio, C. (1978). The genetic control of the molybdoflavoproteins in Aspergillus nidulans. IV. A comparison between purine hydroxylase $\mathrm{I}$ and II. European Journal of Biochemistry 91, 311-316.

MCCully, K. S. \& Forbes, E. (1965). The use of p-fluorophenylalanine with 'master strains' of Aspergillus nidulans for assigning genes to linkage groups. Genetical Research 6, 353-359.

MacDonald, D. W. \& Cove, D. J. (1974). Studies on temperature-sensitive mutants affecting the assimilatory nitrate reductase of Aspergillus nidulans. European Journal of Biochemistry 47, 107-110.

Mackintosh, M. E. \& Pritchard, R. H. (1963). The production and replica plating of microcolonies of Aspergillus nidulans. Genetical Research 4, 320322.

PAGE, M. M. (1971). Genetic and biochemical studies on the catabolism of amines and alcohols in
Aspergillus nidulans. Ph.D. thesis, University of Cambridge.

Page, M. M. \& Cove, D. J. (1972). Alcohol and amine catabolism in the fungus Aspergillus nidulans. Biochemical Journal 127, 17P.

Pateman, J. A., Cove, D. J., Rever, B. M. \& RoBerTs, D. B. (1964). A common co-factor for nitrate reductase and xanthine dehydrogenase which also regulates the synthesis of nitrate reductase. Nature, London 201, 58-60.

Pateman, J. A., Rever, B. M. \& Cove, D. J. (1967). Genetic and biochemical studies of nitrate reduction in Aspergillus nidulans. Biochemical Journal 104, 103-111.

Philippides, D. \& Scazzocchio, C. (1981). Positive regulation in a eukaryote, a study of the $u a \mathrm{Y}$ gene of Aspergillus nidulans II. Identification of the effector binding protein. Molecular and General Genetics 181, 107-115.

Pontecorvo, G., Roper, J. A., Hemmons, L. A., Macdonald, K. D. \& Bufton, A. W. J. (1953). The genetics of Aspergillus nidulans. Advances in Genetics 5, 141-238.

RAND, K. N. \& ARST, H. N., JR (1977). A mutation in Aspergillus nidulans which affects the regulation of nitrite reductase and is tightly linked to its structural gene. Molecular and General Genetics 155, 67-75.

Scazzocchio, C. (1973). The genetic control of molybdoflavoproteins in Aspergillus nidulans II. Use of the NADH dehydrogenase activity associated with xanthine dehydrogenase to investigate substrate and product induction. Molecular and General Genetics 125, 147-155.

Scazzocchio, C. (1980). The genetics of the molybdenum-containing enzymes. In Molybdenum and Molybdenum-Containing Enzymes, pp. 487515. Edited by M. P. Coughlan. Oxford: Pergamon Press.

Scazzocchio, C. \& Darlington, A. J. (1967). The genetic control of xanthine dehydrogenase and urate oxidase synthesis in Aspergillus nidulans. Bulletin de la Société de chimie biologique 49, 1503-1508.

Scazzocchio, C. \& Darlington, A. J. (1968). The induction and repression of the enzymes of purine breakdown in Aspergillus nidulans. Biochimica et biophysica acta 166, 557-568.

Scazzocchio, C. \& Sealy-Lewis, H. M. (1978). A mutation in the xanthine dehydrogenase (purine hydroxylase I) of Aspergillus nidulans resulting in altered specificity. Implications for the geometry of the active site. European Journal of Biochemistry 91, 99-109.

Scazzocchio, C., Holl, F. B. \& Foguelman, A. I. (1973). The genetic control of molybdoflavoproteins in Aspergillus nidulans. Allopurinolresistant mutants constitutive for xanthine-dehydrogenase. European Journal of Biochemistry 36, 428-445.

ScotT, B. R. \& Alderson, T. (1971). The random (non-specific) forward mutational response of gene loci in Aspergillus conidia after photosensitisation to near ultraviolet light $(365 \mathrm{~nm})$ by 8 -methoxypsoralen. Mutation Research 12, 29-34.

Scott, B. R., Alderson, T. \& Papworth, D. G. (1977). The induction of mutations to 2-thioxanthine resistance in inhibitor depleted conidia of $A$ spergillus 
nidulans by $\gamma$-radiation in the presence of oxygen or Sealy-Lewis, H. M., Lycan, D. \& Scazzocchio, C. nitrogen. Mutation Research 45, 21-30.

Sealy-Lewis, H. M., Scazzocchio, C. \& LeE, S. (1978). A mutation defective in the xanthine alternative pathway of Aspergillus nidulans. Its use to investigate the specificity of uaY mediated induction. Molecular and General Genetics 164, 303-308.

(1979). Product induction of purine hydroxylase II in Aspergillus nidulans. Molecular and General Genetics 174, 105-106.

Sorger, G. J., Debanne, M. T. \& Davies, J. (1974). Effect of nitrate on the synthesis and decay of nitrate reductase of Neurospora. Biochemical Journal 140, 395-403. 